\title{
Da Construção de Capacidade Avaliatória em Iniciativas Sociais: Algumas Reflexões
}

\author{
Daniel Braga Brandão \\ Rogério Renato Silva \\ Cássia Maria Carraco Palos
}

\section{Resumo}

Este ensaio discute alternativas de apoio ao desenvolvimento da capacidade avaliatória em organizações da sociedade civil. Nele são debatidos elementos estratégicos para apoiar processos de aprendizagem nas organizações e para fortalecer conquista de autonomia no campo da avaliação. Aborda-se a construção da capacidade avaliatória como processo de construção de sujeitos, e não como um movimento de natureza predominantemente técnica. Com base nos princípios de aprendizagem, autonomia, respeito e participação são propostas cinco dimensões estratégicas para apoiar o desenvolvimento de capacidade avaliatória: 1) a consciência a respeito e a capacidade de lidar com as relações de poder presentes nas ações avaliatórias; 2) a busca de razões e motivação para avaliar as práticas; 3) a construção de um certo grau de identidade organizacional em torno da avaliação; 4) o desenvolvimento de competências no campo da facilitação e ges- tão de processos e da investigação da realidade, necessárias a realização de avaliações; 5) a captação e alocação de recursos para criar as condições de trabalho necessárias aos processos de avaliação.

Palavras-chave: Avaliação. Capacidade avaliatória. Avaliação de programas. Desenvolvimento organizacional. Identidade organizacional.

\section{Mestrando em Educação, PUC/SP \\ Consultor do Instituto Fonte daniel@fonte.org.br \\ Rogério Renato Silva \\ Doutor em Saúde Pública, USP Coordenador Editorial do Instituto Fonte \\ Cássia Maria Carraco Palos Mestre em Saúde Pública, USP Consultora do Instituto Fonte fonte@fonte.org.br \\ Abstract \\ Some \\ Reflections on \\ Building \\ Evaluation \\ Capacity on Social Initiatives}

This essay focuses on building evaluation capacity in civil society organizations. It considers aspects to support the organizational learning process and propose five dimensions to be considered in an evaluation capacity building process: 1) The power that involves the relationship among the stakeholders and its consequences in the decision making process; 2) The reasons and motivations to 
develop the evaluation process; 3) The search to develop an organization understanding of the meaning of evaluation;

4) The need to develop skills in evaluation and 5) The need to raise and manage resources to the evaluation.

Keywords: Evaluation. Capacity building. Organizational development. Organizational identity.

\section{Resumen \\ Constructión de \\ Capacidad en Avaluación}

Este texto trata de la construcción de capacidades en evaluación en organizaciones de la sociedad civil. Aborda el tema orientado por los proceso de aprendijage organizacional y considera cinco dimensiones presentes en la construcción de la capacidad en evaluación en una organización: 1) Las relaciones de poder entre los stakholders y sus consecuencias en las decisiones; 2) Las razones y los motivos para desarrollar una evaluación; 3) La elaboración de una identidad organizacional para la evaluación; 4) La necesidad del desarrollo de competencias en evaluación y 5) La necesidad de garantizar y manejar fondos para la evaluación.

Palabras clave: Evaluación. Capacidad evaluativa. Desarrollo organizacional. Aprendizaje organizacional.

\section{Das razões que nos levaram a \\ escrever este ensaio}

A busca de melhores condições para o enfrentamento dos graves problemas sociais no Brasil, assim como em toda a América Latina, requer investimentos decisivos na pro- dução e sistematização de conhecimentos e práticas a respeito dos problemas da região e, sobretudo, de alternativas conceituais e possibilidades concretas de intervenção e mudança dos cenários de exclusão e dependência que marcam as realidades locais.

Um dos pressupostos mais importantes na busca por melhores políticas públicas ou intervenções sociais que ajudem o processo de desenvolvimento latino-americano encontra-se na necessidade de criar e fortalecer organizações e programas que estruturem modelos de gestão que tenham a reflexão e a aprendizagem entre seus pilares de sustentação. Neste cenário, o desenvolvimento de culturas de avaliação nas organizações da região tem-se constituído como ação estratégica para o fortalecimento organizacional. $\bigcirc$ caso brasileiro não foge à regra.

A ampliação daquilo que podemos denominar de "pensamentos avaliatórios" no Brasil tem sido acompanhado de fatos bastante significativos. Seja por meio da criação da Rede Brasileira de Avaliação no ano de 2002, das dezenas de cursos e seminários sobre avaliação que têm sido promovidos em distintos espaços e organizações ou dos investimentos públicos e privados para a contratação de avaliações internas e externas, parece já existir consenso em torno da necessidade de que projetos e programas sejam avaliados em busca de eficiência, transparência e equidade, ainda que muitos dos desenhos e métodos utilizados se apresentem frágeis e, muitas vezes, pouco democráticos, superficiais e pouco confiáveis.

Ao olharmos para além do horizonte dos discursos existentes neste campo, identificamos desafios complexos e de natureza estruturante para o fortalecimento da cultura da avaliação 
no Brasil. Ao mesmo tempo em que muito se fala em avaliação, alguns fatores seguem determinando um certo grau de dificuldade para que as organizações a incorporem em sua prática cotidiana. Dentre esses fatores, queremos destacar e analisar brevemente os de natureza econômica, os da natureza da formação de gestores, educadores e consultores e os de natureza organizacional.

No que se refere ao aspecto econômico, os recursos alocados para avaliações entre as organizações da sociedade civil ainda são restritos. Rubricas destinadas a estudos avaliatórios ainda são difíceis de negociar e, muitas vezes, entre destinar recursos para realizar ações ou para avaliar ações, não há dúvidas a respeito do caminho seguido. À natureza de programação e prioridade do investimento deste aspecto, soma-se alguma dificuldade das organizações em fazer prognósticos dos custos de uma avaliação. Pode até existir disposição de se investir neste processo, mas existe dificuldade e ausência de parâmetros para definir quanto investir. Mesmo quando os parâmetros recomendados por escolas mais estruturadas são utilizados, como as recomendações da escola americana em destinar 6 a 10\% do orçamento global de um projeto para avaliação, não parece haver qualquer sentido em estabelecer uma relação cartesiana entre tal diretriz e a realidade brasileira. Somente o acúmulo de experiências em processos de avaliação e, sobretudo, a utilização de seus resultados, poderão dar às organizações condições de julgar a relevância de se destinar recursos financeiros a essa finalidade.

Outra questão desafiadora encontra-se na formação de gestores, educadores e consultores para atuarem no campo da avaliação.
Ainda que já reunamos um bom volume de literatura a respeito do tema, sobretudo nos campos da saúde e da educação, ainda são estritas e superficiais os espaços de formação. Tanto a universidade quanto as organizações da sociedade civil que atuam no preparo de gestores e consultores ainda investem pouco em conteúdos em avaliação.

Quanto aos fatores organizacionais, é possível identificar que gestores e educadores convivem com uma polaridade entre fazer e refletir que muitas vezes inviabiliza o investimento em avaliação. A organização do trabalho, o ativismo, as demandas constantes e a permanente escassez de tempo são alguns dos fatores que impedem que um processo de reflexão sobre a prática se enraíze em muitas organizações, mantendo a avaliação em um lugar inviável, ainda que sempre reconhecido como importante.

A partir destes desafios é que procuramos organizar algumas idéias, reunir algumas experiências, e compartilhar com os interessados nossas reflexões. Queremos também destacar três experiências que muito contribuíram para o nascimento deste ensaio. Em primeiro lugar nossa participação no ciclo de "Seminários de Aprofundamento Profissional para o Consultor em Processos de Desenvolvimento", ministrados por Jacques Uljeé (Núcleo Maturi). Em segundo, a coordenação que fizemos do Seminário Construindo Capacidade Avaliatória em Iniciativas Sociais, promovido em parceria com a Ashoka Empreendedores Sociais. Em terceiro, nossa participação como facilitadores na avaliação da quinta edição do Programa de Apoio a Projetos de Atendimento a Crianças e Jovens de 7 a 14 anos na Grande São Paulo, de Vitae Apoio à Cultura, Educação e Promoção Social. 
A força de nossa aprendizagem está na forma como queremos dividir nossas experiências e, portanto, queremos afirmar que este não é um modelo de avaliação, nem consideramos as idéias aqui apresentadas como definitivas. Buscamos colaborar com o debate em torno do tema avaliação e conhecer e discutir idéias e sugestões que permitam incrementar nossa prática avaliatória, fortalecer a cultura de avaliação na América Latina, sobretudo, ajudar o Brasil a alcançar o desenvolvimento social que ajude a erradicar iniqüidades.

\section{Do conceito de avaliação: extrato de uma gramática em expansão}

Há muitas formas de definir o conceito "avaliação", percebido com intensa força polissêmica quando examinamos alguns trabaIhos de autores que escreveram sobre o tema, como Chianca, Marino e Schiesari (2001); Demo (1988); Guba e Lincoln (1988); Patton (1997); Worthen, Sanders e Fitzpatrick (1997); Stake (1995). Neste ensaio adotamos um conceito que, em certa medida, reflete os diálogos que temos estabelecido com as organizações com as quais temos trabalhado. Apontamos para avaliação como um processo de aprendizagem sistemático e intencional que um indivíduo, grupo ou organização se propõe a percorrer para aprofundar a sua compreensão sobre determinada intervenção social, por meio da elaboração e aplicação de critérios explícitos de investigação e análise, em um exercício compreensivo, prudente e confiável, com vistas a conhecer e julgar o mérito, a relevância e a qualidade de processos e resultados. A avaliação leva à ampliação de consciência sobre determinado programa ou projeto o que possibilita que escolhas e decisões maduras possam ser feitas.
Revisamos, com isso, o conceito que apresentamos em artigo anterior (SILVA; BRANDÃO, 2003).

Um dos princípios fundamentais que temos em mente quando nos referimos a um processo avaliatório é o de que uma avaliação não se constitui apenas em um dispositivo técnico, mas sobretudo político. Quando agimos sem que este princípio esteja em nossa consciência, podemos incorrer em um exercício autoritário de poder, como afirma Demo (1988) e fazer com que a avaliação, ao invés de construir sujeitos, torne-se um mecanismo de controle e de coerção que impeça o desenvolvimento.

Entendemos avaliação a partir de uma ótica emancipatória, participativa e colaborativa na qual propósitos e critérios de julgamento são construídos por meio da negociação entre diferentes atores sociais. Temos certeza de que cada sujeito é capaz de avaliar suas ações e nesse fenômeno, de maneira reflexiva, ele se constrói e reconstrói a sua prática. Para nós, o papel de "avaliadores externos" implica em desconforto, em contradição. Agimos como facilitadores, como educadores que, por meio da linguagem da avaliação, procuramos ajudar sujeitos e organizações a se desenvolverem.

\section{Da construção da capacidade avaliatória: alguns princípios}

Nas análises que fizemos de nossas experiências de consultoria, identificamos um conjunto de princípios que entendemos como importantes ao processo de construção de capacidade avaliatória. Ao mesmo tempo em que operam como espelhamento para nossas práticas de avaliação, per- 
cebemos que estes princípios se colocam como um escapulário que nos inspiram em tempos de luz e nos orientam em períodos de sombra. Os princípios são os seguintes:

a. $\bigcirc$ princípio da "aprendizagem" anuncia a avaliação como promotora de oportunidades, espaços e movimentos para que os sujeitos e as organizações aprendam. Avaliar pode se constituir em um processo altamente educativo e transformador da vida social. Para isso é preciso criar objetivos e condições de aprendizagem. Aprenderemos com nossos acertos e erros se avaliarmos criticamente o que fazemos. Sem avaliação não há desenvolvimento.

b. Os princípios do "respeito" e da "autonomia" anunciam que o caminho a seguir em um processo de construção de capacidade avaliatória deve estar orientado pelo contexto cultural, político e estrutural da organização. Como os sujeitos, as organizações vivem seus momentos históricos as entradas forçadas podem mais destruir do que construir capacidades. $\bigcirc$ processo de construção de capacidade avaliatória precisa ser endógeno.

c. Os princípios da "participação" e da "colaboração" se estruturam na crença de que o processo de construção de conhecimento e de produção de conhecimento é individual e social, ganhando sinergia nesta polaridade. Ainda que venhamos a escolher caminhos mais complexos e longos, não se alcançarão práticas justas, organizações socialmente responsáveis e condições sociais equânimes por caminhos que não sejam democráticos.

d. O princípio da "felicidade" surge sensível e naturalmente nas esteiras da sa- bedoria, do bom senso, da arte e, sobretudo, da educação (DEMO, 1988). Felicidade é um processo que contém dimensões mágicas, lúdicas, religiosas, místicas e se constrói na cultura e na história, não simplesmente como superação dos problemas materiais, mas também como expressão sensível de desenvolvimento. Nas palavras de Demo (1988, p. 27), a felicidade está "no clima que pinta, na atmosfera que envolve, na influência que impregna, na solidariedade que inspira" os processos e as relações sociais.

\section{Da construção de capacidade avaliatória: cinco dimensões}

Os processos de construção de capacidade avaliatória com os quais nos envolvemos e que revisamos para produzir este ensaio foram capazes de revelar cinco dimensões a respeito das quais queremos falar agora. Ainda que interligadas, conectadas, dependentes umas das outras, orgânicas, fazemos aqui uma divisão que, acreditamos, nos ajuda a explicitar a compreensão que tivemos do tema. São elas a dimensão do "poder", da "motivação", da "identidade", das "competências" e dos "recursos".

Quando discutíamos e procurávamos articular essas cinco dimensões na forma de uma figura que representasse sua ligação, chegamos ao pentagrama como uma figura simbólica formada por cinco linhas.

Em nossas reflexões e experimentos, nos vimos compreendendo o pentagrama como uma espécie de tradução geométrica do ser humano, ao mesmo tempo em que percebemos cada dimensão que construímos relaci- 
onada a distintas partes do corpo. Nos veio a imagem de Leonardo da Vinci superposta ao pentagrama, cujo sentido foi, ao menos para nós, expressão importante da centralidade do sujeito nesta discussão. $\bigcirc$ poder na cabeça pensante, a identidade á esquerda do peito, a motivação na força da mão, as competências e recursos, sustentando - fisicamente - o processo. Esperamos que nosso esforço criativo provoque reflexões.

\section{Figura 1. Construção de capacidade avaliatória como construção de sujeitos.}

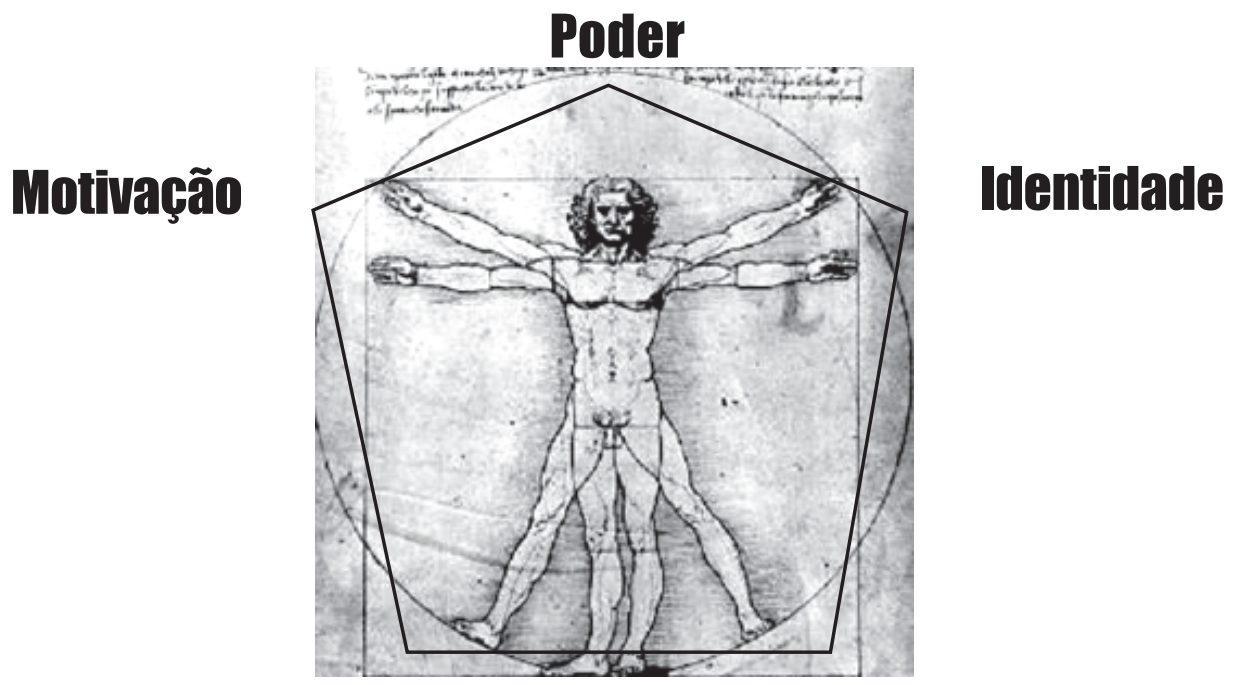

\section{Competências}

Recursos

\section{Do poder}

A arquitetura e a dinâmica das relações sociais estabelecidas em um grupo envolvido em uma avaliação desempenham papel estruturante na construção de capacidade avaliatória em uma iniciativa social. As relações entre a organização financiadora e a organização financiada, entre os sujeitos na organização, com as comunidades com as quais se trabalha e, muitas vezes, com a avaliadora externa, resulta em uma dinâmica complexa de relações que vai determinar o processo decisório e o caminho a ser seguido em uma avaliação. Conseqüentemente o caminho de aprendizagem de um determinado grupo também passa por estas relações.
Na perspectiva da construção da capacidade avaliatória a partir da construção de sujeitos, a participação efetiva e autônoma dos diversos atores envolvidos na iniciativa torna-se a alma do processo de avaliação. Neste sentido, o exercício de compartilhar poder e de equilibrar forças e formas de tomar decisão ocupa posição central no processo. Para alguns, este exercício implica em abrir mão do controle sobre a avaliação, sejam estes gestores da organização ou consultores externos.

O exercício de compartilhar poder se constitui em um espaço privilegiado de negocia- 
ção, conforme observam Guba e Lincoln (1988) ao escreverem a respeito da Avaliação da Quarta Geração. Negociam-se expectativas na forma de perguntas e de desejos. $\mathrm{Ne}$ gociam-se pressupostos e conceitos na forma de indicadores e critérios de julgamento. $\mathrm{Ne}$ gociam-se compreensões da realidade por meio da escolha de métodos de investigação. Negocia-se força e espaço por meio dos compromissos políticos assumidos externa e internamente com o grupo que avalia.

A construção de um ethos político, no qual o porquê e o como avaliar são definidos de maneira colaborativa, tem grande repercussão metodológica no processo de avaliação. Quando operamos com a crença de que a avaliação ganha sentido e relevância à medida que envolve diferentes atores que atuam de maneira autônoma para orientar o processo, é preciso estar preparado para lidar com as implicações concretas que as decisões do grupo trazem para o ato de investigação da realidade. acolhimento destas implicações pode trazer legitimidade e crença no processo.

A discussão de poder que fazemos aqui quer marcar o princípio de que construir capacidade avaliatória é um processo coletivo. Por ser coletivo, transforma-se em um caminho de pavimentação da autonomia dos sujeitos e das organizações. Nas palavras de Freire (1997, p. 35), "ninguém é autônomo primeiro para depois decidir. A autonomia vai se construindo na experiência das várias decisões que vão sendo tomadas" no processo de trabalho. $O$ caminho de construção de capacidade avaliatória será gerador de aprendizagem e autonomia à medida que criar condições para lidar com a dimensão do poder de forma consciente.
Um outro elemento que queremos examinar na dimensão do poder diz respeito à relação entre organizações financiadas e organizações financiadoras. Muitas vezes, a demanda por avaliações surge no seio de organizações financiadoras, que delimitam suas necessidades avaliatórias e definem as perguntas de avaliação que querem responder. Por sua vez, a fonte de informações para responder a essas perguntas costuma ser, na maioria dos casos, as organizações financiadas, bem como as populações com as quais trabalha.

Se este percurso de orientação externa é seguido na avaliação, é comum que os resultados alcançados sejam apresentados ao financiador e sirvam, primariamente, para suas reflexões e decisões, cabendo à organização financiada um lugar de objeto, e não sujeito, da ação avaliatória. Quando falamos em múltiplos atores e na necessidade de que o processo de construção de capacidade avaliatória resignifique relações de poder, imaginamos que a relação entre as organizações financiadas e financiadoras também é objeto desta mudança.

Por fim, não podemos deixar de apontar para a necessidade de que a relação entre organizações e avaliadores externos seja também profundamente revisada em um processo de construção de capacidade avaliatória. Mais do que em qualquer outro tipo de trabalho no campo da avaliação, aqui os avaliadores não são unicamente especialistas em avaliação, não são referências ou autoridades em determinadas áreas de conhecimento, mas sim são atores que ajudam os sujeitos e as organizações a estabelecer sua dinâmica de trabalho e a fazer suas escolhas e descobertas. 


\section{Da motivação}

Se as implicações de poder são tratadas como campo privilegiado no processo de construção de capacidade avaliatória, a necessidade de cuidar da motivação, enquanto campo de interesse e disposição em participar do processo, constitui-se também em uma dimensão importante. Frente a tantas obrigações do do fazer administrativo, financeiro, político, pedagógico, entre outros, depositar energia em processos de avaliação constitui-se um grande desafio.

A motivação não pode, entretanto, ser tratada de maneira estanque. Assim, percebemos a motivação como o fenômeno da significação permanente dos processos de avaliação e de construção de capacidade avaliatória. Se, como afirma Falcão (2001, p. 27), a vontade é "um desejo que cisma que você é a casa dele", esta casa apenas será reconhecida e valorizada à medida que se constituir em espaço permanente de aprendizagem, descobertas e transformações.

A dimensão da motivação se constitui também em campo reflexivo à medida que o sujeito e o processo se reinventam de maneira permanente quando as condições para tal são construídas. Usando uma daquelas frases cuja causa e efeitos são de natureza não linear, somente terá espaço e sentido para os sujeitos os processos de avaliação que forem desejados por eles, ao mesmo tempo em que só serão desejados os processos avaliatórios que tiverem sentido para os sujeitos.

Para Sanders (2003), quatro razões dificultam a incorporação da avaliação como parte estratégica da organização, sendo elas (a) o fato de que os sujeitos desconheçam os benefícios das avaliações, (b) o fato dos elevados investimentos de tempo e recursos nas avaliações, (c) a inexistência de sujeitos que desempenhem certo papel de liderança frente aos processos de avaliação e (d) o fato da pouca ou nenhuma utilização das avaliações para aprender e mudar. A estas observações acrescentaríamos, de forma radicular, o fato da insistência em processos exógenos, burocráticos, persecutórios e não participativos.

Enfrentar estas condições, hegemônicas em muitos cenários, constitui-se como peça chave para atribuir sentido e trazer motivação ao processo de construção de capacidade avaliatória. Tratar a avaliação de forma transparente e democrática, relacioná-la a espaços e momentos de aprendizagem e decisão, encontrar lideranças interessadas em problematizar e motivar os grupos sociais a avaliarem suas ações, são algumas das alternativas que contribuem para que os processos se tornem viáveis ${ }^{1}$ e sustentáveis.

\section{Da identidade}

Algumas ferramentas aplicadas à gestão de iniciativas sociais são amplamente reconhecidas como capazes de construir e significar conceitos e práticas, como a elaboração de projetos, o planejamento estratégico e a sistematização. Neste conjunto a avaliação se afirma como ferramenta técnica-política efetiva para promover tais fenômenos.

Em si mesma, a avaliação espelha sujeitos e organizações de maneira significativa. $\bigcirc$ que queremos, no que acreditamos, o que valorizamos, com quem nos relacionamos, o que negociamos e como julgamos, constitu-

'Viabilidade: assegurar que uma avaliação será feita de maneira realista, prudente, diplomática e moderada (SANDERS, 1994). 
em-se categorias com as quais operamos nos processos de avaliação e que irão revelar de forma marcante nossa identidade nos processos. Por isso mesmo, a dimensão da identidade é de grande importância na construção de capacidade avaliatória. É na construção da identidade que percebemos os outros e o que nos difere e nos aproxima daqueles com os quais trabalhamos.

Se por um lado nos preparamos para lidar com poderes e criar espaços de construção e por outro enfrentamos a atribuição permanente de sentido, uma terceira dimensão nos convida a explorar gramáticas, pressupostos e práticas. É nesta dinâmica que se irmanam os elementos que nos ajudarão a responder, como sujeitos e grupos sociais: $\bigcirc$ que entendemos por avaliação? Por que avaliamos? $\bigcirc$ que queremos aprender? Como utilizaremos o que aprendemos em nossas ações? Como aprenderemos?

Para além das definições em torno dos próprios processos de avaliação, o que temos observado participativamente é que as avaliações criam espaços privilegiados para que a prática dos sujeitos seja conceituada e para que seus pressupostos e conceitos sejam revisitados e, muitas vezes, negociados e revisados. Os processos de identificação de perguntas e de definição de indicadores (critérios, sinais, marcadores, evidências) de avaliação, são campos férteis para se produzir e reinventar conceitos.

processo de construção de capacidade avaliatória é um processo de construção de identidades, por isso também é processo que fortalece a construção de sujeitos. Ampliar consciências, aprofundar conhecimentos, revisitar e revisar práticas, aprender, mudar. Por isso falamos em identidade.

\section{Das competências}

Os processos de avaliação e de construção de capacidade avaliatória em iniciativas sociais não avançam quando se constituem em mera sucessão de métodos e técnicas que se aplica para "desvendar" a realidade. Avançam sim quando se conformam em um caminho de desenvolvimento no qual as escolhas, elaborações e a organização do trabalho são produzidos de forma dinâmica, convivendo com reinvenção permanente.

Os processos avaliatórios oferecem espaços nos quais muitas vezes nos confrontamos com nosso conhecimento técnico no campo da investigação, com nossas habilidades de facilitação e nossa forma de gerir processos. Por tudo isso percebemos que, ao mesmo tempo em que articulamos poderes, que apoiamos motivações e que provocamos construção de identidades, precisamos nos preparar para lidar com estas dimensões de forma sensível e eficaz, ao mesmo tempo em que cuidamos desse "lugar de investigação" sem o qual não há avaliação, ou confiança em seus resultados.

Assim articulamos três campos cujo conteúdo queremos compartilhar. As competências de facilitação de processos, de gestão de processos e de investigação da realidade compõem um cenário relevante para o desenvolvimento de sujeitos na área. Entendemos que o cenário de competências é um campo de articulação das demais dimensões analisadas aqui, é um campo no qual caminhamos em busca de apoiar processos que levem à reflexão, aprendizagem e desenvolvimento. A Figura 2, a seguir, ilustra este cenário. 
Figura 2. Cenário de competências em avaliação.

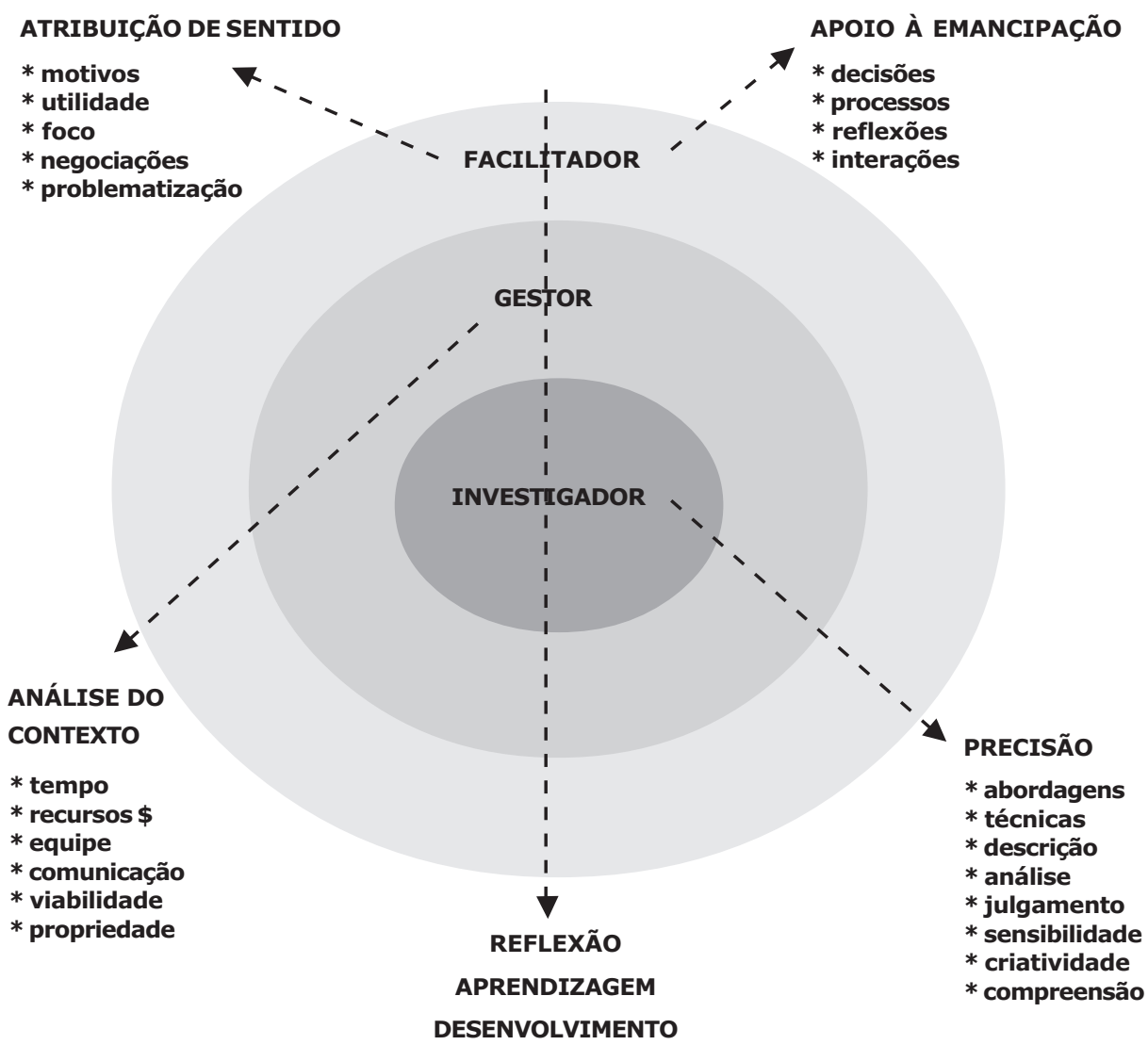

a) a competência para a facilitação de processos

A facilitação de processos é competência fundamental para garantir que as dimensões aqui analisadas consigam existir e buscar pontos de equilíbrio que assegurem o desenvolvimento dos sujeitos e grupos. A facilitação envolve trabalho com sentidos, com significados, com articulações, com negociações, com construções, com leituras da realidade, com acolhimento e com provocação.
Percebemos a facilitação como competência chave para atribuir sentido a processos de avaliação. Por isso lida com poderes, motivações e identidade de maneira intensa. Além do mais, é a facilitação que articulará as competências de gestão e de investigação da realidade a fim de garantir processos viáveis e confiáveis. Toda a construção técnica da avaliação se dará a partir das habilidades de facilitação. A seguir identificamos seis habilidades importantes, entre tantas outras. 
- Capacidade de ouvir de forma aberta e sensível os integrantes do grupo;

- Capacidade de trabalhar de forma compreensiva as necessidades do grupo;

- Capacidade de problematizar questões, de provocar e estimular reflexões sobre o projeto e os elementos da avaliação;

- Habilidade para ajudar o grupo a construir compreensões e respostas, sem levá-las prontas;

- Capacidade de zelar pelo processo de trabalho do grupo, cuidando de procedimentos, relações e estrutura;

- Capacidade de agir com profundo respeito pelas criações do grupo, acolhendo-as de maneira integral.

\section{b) a competência para gestão de processos}

Trata-se da competência em lidar com as variáveis internas e externas aos processos de avaliação, tais como o tempo, os recursos financeiros, a gestão de equipes de trabalho, os planos de avaliação, a comunicação, entre outras coisas. As habilidades para enfrentar estes desafios serão fundamentais para que os processos de avaliação sejam sustentáveis.

\section{c) a competência para investigação da realidade}

Em essência, os processos de avaliação têm na necessidade de investigar a realidade um eixo comum e determinante para sua existência. Por isso mesmo a necessidade de desenvolver competências no campo da investigação é vista com grande importância para os sujeitos e organizações que querem desenvolver capacidade avaliatória.

É a competência para investigar a realidade que terá peso determinante na em as- segurar a precisão ${ }^{2}$ do processo e, em conseqüência, sua confiabilidade por parte dos diferentes interessados. A necessidade de escolher as abordagens mais adequadas, de garantir os métodos mais apropriados, profundos e capazes de revelar, de compor quantidade e qualidade de forma harmônica, são os desafios que se colocam no caminho daqueles que se interessam por avaliação.

Fugir do cientificismo ingênuo e do relativismo fundamentalista coloca aos sujeitos o desafio de estabelecer formas confiáveis de explorar a realidade, de retratar os fatos, de aprofundar compreensões e de revelar informações que soem verdadeiras aos interessados. Por fim, como afirma Guba e Lincoln (1988), o uso exclusivo do método científico fecha as portas para maneiras alternativas de se pensar a respeito do objeto da avaliação.

\section{Dos recursos}

A dimensão final a respeito da qual fazemos breves comentários é a dimensão dos recursos. Consideramos recursos o conjunto de elementos que são consumidos em processos de avaliação e que, por isso mesmo, implicam em escolhas, definição de limites e certo controle. Tempo das pessoas, contratações externas, equipamentos, materiais e estrutura de apoio muitas vezes serão necessários a determinados tipos de processos de avaliação.

Ainda que muitos desenhos avaliatórios, sobretudo os de natureza processual, demandam pouco ou quase nenhum investimento direto, certos casos precisarão ser analisados e ponderados com cuidado, a fim de que a avaliação não se torne custosa e pouco efetiva, traços que contribuiriam

\footnotetext{
2 Precisão: assegurar que uma avaliação irá revelar e produzir informações tecnicamente adequadas sobre os aspectos que determinam o mérito e a relevância do programa avaliado (SANDERS, 1994).
} 
para que cultura avaliatória não se enraizasse nos sujeitos e nas organizações.

\section{Da síntese das dimensões}

As dimensões apresentadas assumem seu sentido de existência ao se fazerem úteis no apoio ao desenvolvimento de iniciativas ava- liatórias. No estímulo à reflexão, na reordenação da prática e na abertura para novas percepções e sentimentos é que as cinco dimensões ganham vida. Para auxiliar este processo, propõe-se uma configuração didática das dimensões discutidas ao longo deste ensaio, apresentada no quadro 1.

\section{Quadro 1. Síntese das dimensões capacidade avaliatória de uma iniciativa social' .}

\begin{tabular}{|c|c|c|c|}
\hline Dimensão & Premissa & O que gera & Perguntas chave \\
\hline $\begin{array}{l}\text { Poder } \\
\text { (O que } \\
\text { podemos?) }\end{array}$ & $\begin{array}{l}\text { Agir em } \\
\text { liberdade }\end{array}$ & $\begin{array}{c}\text { Participação e } \\
\text { comprometimento }\end{array}$ & $\begin{array}{l}\text { Quem será envolvido? } \\
\text { Quais suas aspirações? } \\
\text { Qual o papel de cada um? } \\
\text { Qual será a participação } \\
\text { desses atores? } \\
\text { Que conflitos existem? } \\
\text { Como tomaremos decisões? }\end{array}$ \\
\hline $\begin{array}{l}\text { Identidade } \\
\text { (O que somos } \\
\text { e pensamos?) }\end{array}$ & Conceitualizar & Alinhamento & $\begin{array}{l}\text { O que entendemos por avaliação? } \\
\text { Por que iremos avaliar? } \\
\text { Para que iremos avaliar? } \\
\text { Como vamos utilizar os resultados? } \\
\text { O que buscamos aprender? } \\
\text { O que iremos avaliar } \\
\text { (pergunta avaliatória)? }\end{array}$ \\
\hline $\begin{array}{l}\text { Vontade } \\
\text { (O que } \\
\text { queremos?) }\end{array}$ & Desejar e inspirar & Movimento & $\begin{array}{l}\text { Que sentimentos a avaliação } \\
\text { nos desperta? } \\
\text { Queremos avaliar? } \\
\text { Estamos dispostos a abrir } \\
\text { espaço para a avaliação? } \\
\text { Quem pode liderar o processo? }\end{array}$ \\
\hline $\begin{array}{l}\text { Competências } \\
\text { (O que } \\
\text { sabemos?) }\end{array}$ & $\begin{array}{l}\text { Reconhecer } \\
\text { competências e } \\
\text { habilidades } \\
\text { no grupo }\end{array}$ & $\begin{array}{c}\text { União e busca } \\
\text { do desenvolvimento } \\
\text { do grupo }\end{array}$ & $\begin{array}{l}\text { Como iremos avaliar? } \\
\text { Quais conhecimentos e } \\
\text { habilidades temos (eu e o outro)? } \\
\text { O que precisamos desenvolver? }\end{array}$ \\
\hline $\begin{array}{l}\text { Recursos } \\
\text { (O que } \\
\text { conseguimos } \\
\text { agora?) }\end{array}$ & $\begin{array}{l}\text { Reconhecer o que } \\
\text { se tem e o que é } \\
\text { necessário }\end{array}$ & $\begin{array}{l}\text { Orientação pela } \\
\text { realidade: } \\
\text { "Pé no chão" }\end{array}$ & $\begin{array}{l}\text { Qual tempo/ envolvimento } \\
\text { vamos dispor? } \\
\text { Qual o prazo? } \\
\text { De quais recursos dispomos? } \\
\text { O que será necessário captar? }\end{array}$ \\
\hline
\end{tabular}

3 As perguntas entre parênteses foram sugeridas por Cláudia Mara de Melo Tavares, durante a oficina "Iniciativas Inovadoras em Avaliação de Projetos e Programas Sociais", por ocasião do V Congresso Nacional da Rede Unida, Londrina, PR, maio de 2003. 


\section{Das considerações finais}

Acreditamos que a construção de capacidade avaliatória em iniciativas sociais pode encontrar boas reflexões com base na experiência que apresentamos aqui. Sabemos também que estas dimensões são dinâmicas e não obedecem a um processo equânime de desenvolvimento. Há muito a ser feito, descoberto, revisado e aprofundado. Nossa contribuição é circunscrita a este pressuposto.

Uma avaliação requer autenticidade, curiosidade e rigor, o que nos coloca $\circ$ desafio permanente de lidar com a incerteza, de sermos compreensivos com a realidade e de buscarmos, insistentemente, a construção de sujeitos.
A construção da capacidade avaliatória como processo de construção de sujeitos está conjugada a um processo pedagógico de perspectiva emancipatória que colabora com o fortalecimento de indivíduos, grupos e organizações. Está associada à profunda crença de que mulheres e homens podem transformar a si próprios e a sua interação com os outros, num refazer do mundo e da própria história. Está relacionada à percepção de que qualquer ação empreendida deve alcançar a liberdade de homens e mulheres. Significa dizer que se busca construir um conhecimento que enxergue além da indiferença cega e da ilusão ingênua.

Significa acreditar que se pode compartilhar uma utopia.

\section{Referências}

CHIANCA, T. C.; MARINO, E.; SCHIESARI, L. M. C. Desenvolvendo a cultura de avaliação em organizações a sociedade civil. São Paulo: Instituto Fonte, Global; 2001.

DEMO, P. Avaliação qualitativa. 2. ed. São Paulo: Cortez, 1988.

FALCÃO, A. Mania de explicação. 5. ed. São Paulo: Salamandra, 2001.

FREIRE, P. Pedagogia da autonomia. São Paulo: Paz e Terra, 1997.

GUBA, E.; LINCOLN, Y. The fourth evaluation generation. Thousand Oaks, Calif.: Sage Publications, 1988.

JOINT COMMITTEE ON STANDARDS FOR EDUCATIONAL STANDARDS. The program evaluation standards. 2. ed. Thousand Oaks, Calif.: Sage Publications, 1994.

PATTON, M. Q. Utilization-focused evaluation: the new century text. 3. ed. Thousand Oaks, Calif.: Sage Publications, 1997.

SANDERS, J. R. Mainstreaming evaluation. In: BARNETTE, J. J.; SANDERS, J. R. (Ed.). The mainstreaming evaluation. San Francisco: Jossey-Bass, 2003. 
SILVA, R. R.; BRANDÃO, D. B. Os quatro elementos da avaliação. São Paulo: Instituto Fonte, 2003. Disponível em: <www.fonte.org.br>. Acesso em: 29 ago. 2005.

STAKE, R. E. The art of case study research. Thousand Oaks, Calif.: Sage Publications, 1995.

WORTHEN, B. R.; SANDERS, J. R.; FITZPATRICK, J. L. Program evaluation: alternative approaches and practical guidelines. 2. ed. New York: Longman, 1997.

Recebido em: 14/01/2005

Aceito para publicação em: 27/06/2005 